\title{
Response of sediment-dwelling annelida community in relation to geochemical parameters in the Gorgan Bay, Caspian Sea
}

\author{
K. D. Bastami $\cdot$ M. Taheri $\cdot$ H. Bagheri $\cdot$ \\ M. Y. Foshtomi $\cdot$ S. Ganji $\cdot$ S. Haghparast • \\ F. Soltani $\cdot$ A. Hamzehpoor $\cdot$ B. Karimi
}

Received: 21 July 2013/Revised: 12 July 2014/Accepted: 9 August 2014/Published online: 26 August 2014

(C) Islamic Azad University (IAU) 2014

\begin{abstract}
This study aimed to investigate the population of annelida communities in relation to environmental factors and heavy metals accumulated in sediments of the Gorgan Bay. The pollution load index and potential ecological risk (PER) were calculated. The results indicated mean concentrations (ppm) of heavy metals were (mean $\pm \mathrm{SD}$ ) $\mathrm{Pb}: 11.5 \pm 4.88, \quad \mathrm{Cu}: 18 \pm 8.83, \mathrm{Zn}$ : $42 \pm 22.15$, Ni: $29.20 \pm 14.68$, Co: $10.56 \pm 14.68$, As: $7.77 \pm 2.12$, Sr: $1,449 \pm 902.59$ and V: $26.64 \pm 10.25$. Considering PER, sediments of the Gorgan Bay had low ecological risk. Based on abundance data, dominant species were Streblospio gynobranchiata, Nereis diversicolor, Tubificoides fraseri and Tubificidae unknown, respectively. Results of redundancy analysis displayed that $T$. fraseri and $N$. diversicolor were associated with high values of Sr. All
\end{abstract}

K. D. Bastami $(\bowtie) \cdot$ M. Taheri · H. Bagheri ·

M. Y. Foshtomi - A. Hamzehpoor

Iranian National Institute for Oceanography and Atmospheric

Science (INIOAS), No. 3, Etemadzadeh St., Fatemi Ave.,

1411813389 Tehran, Islamic Republic of Iran

e-mail: darvish_60@yahoo.com

S. Ganji

North Tehran Branch, Faculty of Science and Technology,

Islamic Azad University, Tehran, Islamic Republic of Iran

S. Haghparast

Faculty of Fishery, Gorgan University of Agricultural Sciences and Natural Resources, P.O. Box 45165-386, Gorgan, Islamic

Republic of Iran

F. Soltani

Young Researchers and Elites Club, North Tehran Branch, Islamic Azad University, Tehran, Islamic Republic of Iran

B. Karimi

Marine Ecology, Science and Research Branch, Islamic Azad

University, Tehran, Islamic Republic of Iran the species were negatively correlated with As. There were positive correlation between $S$. gynobranchiata and $N$. diversicolor with values of clay, salinity, depth and silt. The present study provided the relative importance of heavy metals and environmental variables which partly assist in structuring assemblages of annelida in a transitional area.

Keywords Annelida - Environment - Redundancy analysis $\cdot$ Potential ecological risk $\cdot$ Heavy metals · Gorgan Bay $\cdot$ Caspian Sea

\section{Introduction}

Characteristic features of benthic communities such as sedentary lifestyle or limited mobility, relatively long life cycle, a wide variety of species altogether with different sensitivities to environmental stressors, their important role in cycling nutrients at sediment-water interface are beneficial in quality evaluation of aquatic ecosystems (Dauvin 2008; Borja et al. 2008).

The community structure of benthic macroinvertebrates can be influenced by sediment particle size (Van Hoey 2004), salinity (Pinder et al. 2005), availability of food and nutrients (Frost et al. 2009), anthropogenic pollution and pH (Goto and Wallace 2010).

Pollution affects community structure of benthic macroinvertebrates, and such community exhibits species-specific responses to a number of given anthropogenic stressors (Goto and Wallace 2010). Introduction of contaminants into natural environment results in adverse changes such as the loss of sensitive species (Dauvin 2008), while tolerant species may grow faster because their competitors have already been eliminated by the toxicant (Connell et al. 1999). This would cause a decrease in the 
number, diversity and abundance of tolerant species as well as a shift in species composition.

Benthic invertebrates are considered as the most vulnerable community due to the dependence of their community structure on the sediment and can be affected by an increasing trend of heavy metals. Metals absorption by these organisms is pertained to each individual metal concentration and chemical forms of metals transmission. Benthic organisms have been widely used in marine environmental monitoring, particularly in the toxicity of sediments, as they are directly affected by the pollutants in such sediments (Brown and Luoma 1995; Lotufo et al. 2001; Zorita et al. 2007).

Worms are often the main benthic species in estuarine sediments, and their sedentary lifestyles are ideal for examining site-specific contamination issues (Scaps 2002). Polychaetes can be found at all latitudes and depths and are suitable indicators of organic pollution due to their high abundance and sensitivity to different amounts of organic matter in sediments (Fauchald 1977). Some oligochaetes have been described as good organic pollution indicators due to their high dominance in enriched sediments (Gamito 2008).

Gorgan Bay located at the southeastern section of the Caspian Sea with $60 \mathrm{~km}$ length and $12 \mathrm{~km}$ width is a semienclosed basin, as it receives no wave's energy from the Caspian Sea. The bay is mostly affected by the currents originating from inside the basin. This area is best known for its high economical and ecological importance as a fishing and recreational ground because of appropriate biological conditions for aquatic animals. The Gorgan Bay is considered as an ultimate sink for water flowing from Gharehso River. The Gorgan River faces the Caspian Sea at vicinity of the bay mouth at the northeast part.

With the above scenario, the objectives of the present study are: (1) to assess the extent of heavy metals and ecological risk and (2) to determine the relationships between annelida communities, environmental parameters and heavy metals deposited in sediments of the Gorgan Bay in August 2010.

\section{Materials and methods}

Benthic sample collection and analysis

Benthic macroinvertebrates were collected using Van-Veen grab from sediments of the Gorgan Bay in August 2010 (Fig. 1). Three replicates were collected at each sampling site. The geographical locations of the sampling sites were recorded using a hand-held GPS (eTrax, Garmin). Immediately after collection, sediment samples were sieved using a $0.5-\mathrm{mm}$ mesh sieve, fixed in $4 \%$ buffered formalin solution and stained with rose bengal. Then, all the annelida were separated under a dissection microscope and identified to the lowest taxon possible.
Fig. 1 The locations of the sampling sites at the Gorgan Bay

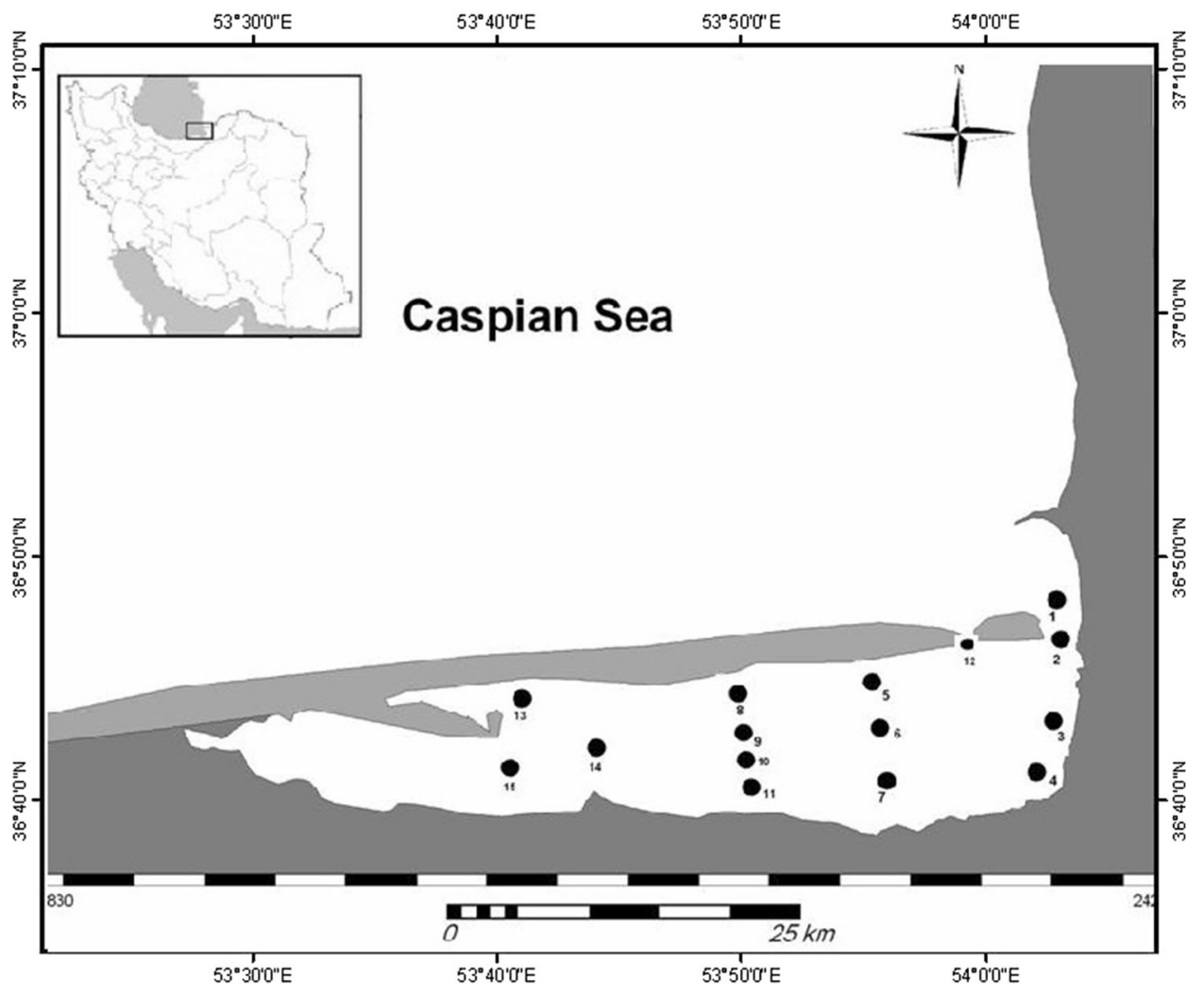


Determination of physical and chemical parameters

In each sampling site, environmental parameters were measured in the water column using a CTD probe (Ocean Seven 316 , Italy) that allows high resolution and simultaneous monitoring of pressure (expressed as water depth), temperature, $\mathrm{pH}$, electrical conductivity (EC), dissolved oxygen concentration, total chlorophyll- $a$ concentration, turbidity and light backscatter. In this study, we used temperature, salinity and depth data.

Heavy metals analysis

Another sediment sample was collected using Van-Veen grab for heavy metals analysis. After sampling, sediment samples were packed, carried to the laboratory in iced boxes and stored at $4{ }^{\circ} \mathrm{C}$ until analysis. After sediment samples were dried in an oven and stone pieces were removed, they were ground using a hand mortar. For digestion of sediment samples, $0.5 \mathrm{~g}$ of each sediment sample was added with a mixture of $\mathrm{HCl}-\mathrm{HNO}_{3}-\mathrm{H}_{2} \mathrm{O}$ (with the ratio of 1:1:1 v/v) and heated at $95{ }^{\circ} \mathrm{C}$ during $1 \mathrm{~h}$. In the laboratory, the samples were analyzed (As, $\mathrm{Ni}, \mathrm{Zn}$, $\mathrm{V}, \mathrm{Sr}, \mathrm{Pb}, \mathrm{Cu}, \mathrm{Co}$ and $\mathrm{Al}$ ) using inductively coupled plasma mass spectroscopy (ICP-MS; Perkin-Elmer ELAN9000) at ACME Analytical Laboratories Ltd. in Canada (http:// www.acmelab.com/cfm/index.cfm). ACME is currently registered with ISO 9001:2000 accreditation. Standard samples (Oreas $45 \mathrm{~Pa}$, DS7 and DS8) were used to monitor the performance of the instrument and data quality. The analytical results of the quality control samples show good agreement with the certified values (recoveries ranging 94.04-107.89\%).

Determination of organic matter in sediments

To assess total organic matter, sediment samples were dried at $70{ }^{\circ} \mathrm{C}$ for $24 \mathrm{~h}$ and then combusted in an oven at $550{ }^{\circ} \mathrm{C}$ for $4 \mathrm{~h}$. Total organic matter, as described by Abrantes et al. (1999), was measured by the following equation:

Total organic matter $(\mathrm{TOM}, \%)=[(B-C) / B] \times 100$

where $B$ and $C$ are the weights of dried sediment before and after combusting in the oven, respectively.

Determination of sediments grain size

Sediment grain size analysis was made from soil samples collected in separate polythene bags. For that, samples were air-dried and sieved through a mechanical sieve to remove shells, debris, etc. Dried sediment samples were subjected to size fraction analysis following the procedure of Wentworth (1992). Hundred gram of sample was taken and sieved through a $62-\mu \mathrm{m}$ mesh-sized screen for $10 \mathrm{~min}$ in a mechanical sieve shaker. The sample remained in the sieve was weighed and treated as sand. Sediment samples that passed through the sieve were the silt and clay. The silt and clay fractions were then separated by means of pipette method, described by Lindholm (1987).

Method of pollution load index (PLI) and potential ecological risk (PER)

To assess the sediment environmental quality, an integrated PLI of six metals was calculated as suggested by Suresh et al. (2011).

$\mathrm{PLI}=\left(\mathrm{CF}_{1} \times \mathrm{CF}_{2} \times \mathrm{CF}_{3} \times \cdots \mathrm{CF}_{n}\right)^{1 / n}$

where CF metals is the ratio between the content of each metal to background values,

$\mathrm{CF}_{\text {metals }}=\mathrm{CH}_{\text {metal }} / \mathrm{CH}_{\text {back }}$.

Potential ecological risk index was also introduced to assess the contamination degree of heavy metals in the present sediments. The equations for calculating PER were proposed by Hakanson (1980) as the following:

$\mathrm{PER}=\sum E$.

$E=T C$.

$C=C_{a} / C_{b}$.

where $C$ is the single element pollution factor, $C_{a}$ is the content of element in samples, and $C_{b}$ is the reference value of element. The sum of $C$ for all the metals examined represents integrated pollution degree $(C)$ of the environment. $E$ is the PER index of an individual element. $T$ is the biological toxic factor of an individual element, which is determined for $\mathrm{Cu}=\mathrm{Pb}=5, \mathrm{Zn}=1, \mathrm{As}=10$ and $\mathrm{Ni}=6$ (Guo et al. 2010; Fu et al. 2009). PER is a comprehensive potential ecological index, which is the sum of $E$. It represents the sensitivity of biological community to toxic substances and illustrates PER caused by overall contamination.

Statistical analysis

Univariate indices of total annelida abundance [density ( $N$, ind. $\left.0.03 \mathrm{~m}^{2}\right)$, number of species $(S)$, species diversity [Shannon-Weaner index, $\left.\left(H, \log _{2}\right)\right]$, species richness [Margalef's $(d)$ ] and evenness Pielou's $(J)$ were computed using statistical package of PRIMER version 5 (Clarke and Warwick 2001). Significant differences in the parameters among different sampling sites were calculated by one-way analysis of variance (ANOVA) using the SPSS statistical 
package program (version 19). Prior to analysis, normality and homogeneity variance assumptions were checked and, when necessary, a $\log (1+x)$ transformation data were utilized. Comparisons of indices were carried out using Duncan's multiple range tests with $95 \%$ of confidence limits. A Pearson correlation analysis was performed to test the relationship among various biological and environmental parameters.

Difference in density annelida community in sites was indicated by a non-metric multidimensional scaling (nMDS) ordination, which was derived from Bray-Curtis similarity metrics and a fourth-root transformation. The reliability of nMDS representations of assemblage similarities was assessed with their stress values; stress $<0.2$ was considered to be acceptable (Clarke and Warwick 2001). This analysis was also performed using PRIMER 5.

In order to assess relationships between the annelida community composition and environmental variables, first we performed a detrended canonical correspondence analysis (DCCA) on abundance data, but without data transformation, to obtain the length of the gradient along the first axis, according to ter Braak and Šmilauer (2002); when the gradient length is $<3$, a redundancy analysis (RDA) is recommended, and when gradient length is $>4$, a CCA is recommended. Our data exhibited short gradients in DCCA analysis, and therefore, the linear model RDA was considered as appropriate model for this dataset. All data were $\log (x+1)$ transformed in order to reduce the influence of common taxa. Further, data were transformed (centered and standardized by species), to harmonize different scales (Lepš and Šmilauer 2003). Monte Carlo permutation test was performed to determine whether the relation between species abundances and the measured physicochemical variables was significant. These analyses were performed using the software of CANOCO 4.5 (ter Braak and Šmilauer 2002).

\section{Results and discussion}

\section{Environmental variables}

Gorgan Bay depth ranges from 0.62 to $4.12 \mathrm{~m}$ with an average value of $1.84 \pm 1.14 \mathrm{~m}$. The highest and the lowest depths were observed at stations 6 and 10, respectively. Salinity was between 4.95 and 12.40 ppt. Average value of temperature recorded in the Gorgan Bay was $26.08 \pm 1.03{ }^{\circ} \mathrm{C}$.

Regarding to the analysis, TOM content in sediment of the Gorgan Bay was 1.75-9 \% (averaged $4.45 \pm 1.72 \%$ ) which exhibited the highest and the lowest amounts at stations 15 and 14, respectively. Likewise, the sand, silt and clay contents averaged $23.38 \pm 27.56,36.61 \pm 18.3$ and $39.76 \pm 14.40 \%$, respectively (Table 1 ).

Univariate analysis of annelida community structure

Altogether, the identified annelida communities in the Gorgan Bay belonged to two classes, three families and three species. Annelida families included: Spionidae, Nereidae and Tubificidae.

Among all the species, Streblospio gynobranchiata was identified at all sampling stations as it was similar for Nereis diversicolor except for station 15 where no individuals of this species were found. Tubificoides fraseri was detected at all sampling stations except stations 3 and 7 (Table 2). The highest density of S. gynobranchiata was observed at station 1, T. unknown at station 8 and T. fraseri and $N$. diversicolor at stations 10 and 11 , respectively.

Based on abundance data, dominant species were $S$. gynobranchiata, $N$. diversicolor, $T$. fraseri and Tubificidae unknown, respectively. The presence of $S$. gynobranchiat at all sites might be due to their ecological importance in the Gorgan Bay as it is an invader species in the Caspian Sea probably introduced from ship's ballast water.

As deduced from Table 2, the most density was displayed at station 1 while stations 6 and 14 exhibited the lowest one. Overall mean density of annelida inhabiting in sediment of the Gorgan Bay was $65.46 \pm 45.10$ (ind. $0.03 \mathrm{~m}^{-2}$ ). More precisely, significant differences $(P<0.05)$ were observed in density of all the studied sampling stations. Shannon diversity index $\left(H^{\prime}\right)$ varied from 0.21 to 1.44 which exhibited the most and the least amounts at stations 9 and 2, respectively. Average value of Shannon index was $0.76 \pm 0.39$ and displayed significant difference $(P<0.05)$ between station 10 with sampling stations $2,3,4,6,7,11$ and 12 (Table 2). Evenness index $\left(J^{\prime}\right)$ ranged from 0.13 to 0.87 with the lowest and the highest levels at stations 2 and 15, respectively. The mean value of Evenness index was accounted for $0.51 \pm 0.20$ (Table 2). The species richness (d) varied from 0.20 to 0.69 with the highest and the lowest values at stations 9 and 2, respectively. In Gorgan Bay, species richness averaged $0.42 \pm 0.14$ and exhibited significant difference between sampling station 2 with sites 8,9 and 13 as well as between station 9 with sites 2 , 3 and $7(P<0.0 .5)$.

According to nMDS analysis using density, annelida communities formed four distinctive groups in which stations 2, 3, 5, 9 and 11 were included in the first group; stations $1,4,8$ and 10 in the second group; stations 7, 12, 13 and 15 in the third group and stations 6 and 14 in the fourth group (Fig. 2). nMDS plot showed sites with a higher annelida density at the right extreme, while at the left extreme appeared sites with lower annelida density. 


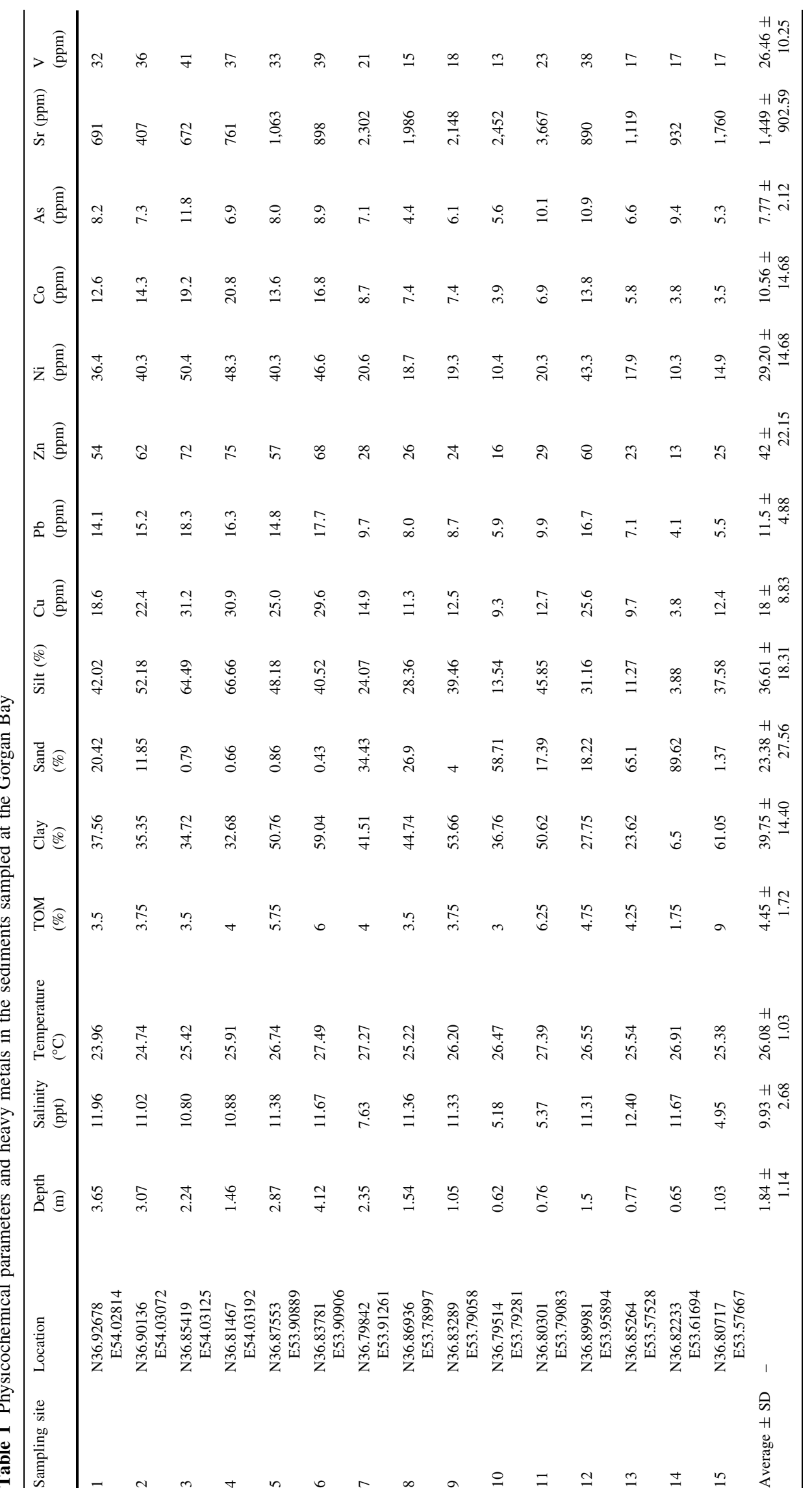




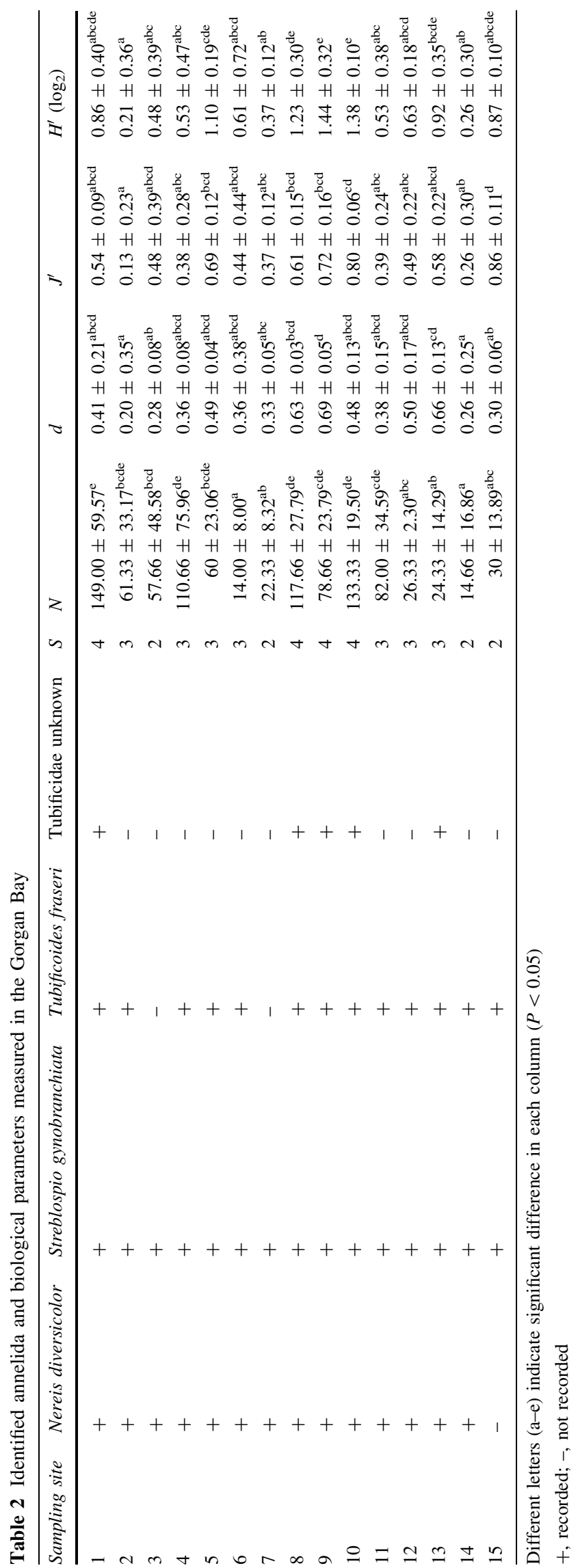

Generally, density of annelida in eastern part was higher than western part of Gorgan Bay.

A wide range of biological indices based on benthic communities has been applied for ecosystem evaluation. Generally, estuaries and inlets are exposed to environmental stressors much more than other regions.

In a healthy environment, Shannon-Wiener species diversity is in the range of 2.5-3.5 (Khan et al. 2004). Family-level diversity values are generally lower than species- and genus-level diversity (Gesteira et al. 2003). In this study, the average value of Shannon species diversity index was $0.76 \pm 0.39$. Shannon diversity index accounts for less than 1 in extremely polluted waters, $1-3$ in moderately polluted water and more than 3 in non-polluted water bodies (Wilhm and Dorris 1966). According to above-mentioned, stations 5, 8, 9 and 10 are moderately polluted sites and the others reflect extreme pollution, clearly suggesting that annelida communities in the Gorgan Bay are influenced by the stressors.

Vincx and Heip (1987) stated that the use of diversity indices as the only tool in monitoring programs is sometimes doubtful as statistically significant changes in indices can be emphasized only if intense variations in the assemblage structure occur.

Generally, number of species decreases in highly disturbed communities which resulted in the dominance of one or two specific species and then the value for Evenness index decreases much more. In the present study, mean value for Evenness index in the Gorgan Bay was calculated for $0.51 \pm 0.20$. Low values of evenness in a large part of study area were indicative of imbalanced benthic assemblages (Díaz-Castaneda and Harris 2004).

Spatial distribution of heavy metals in sediments

Range of heavy metals concentration (ppm) was $\mathrm{Cu}$ : 3.8-31.2, Pb: 4.1-18.3, Zn: 13-75, Ni: 10.3-50.4, Co: 3.5-20.8, As: 4.4-11.8, Sr: 407-3,667 and V: 13-41. The most concentrations of $\mathrm{Cu}, \mathrm{Pb}, \mathrm{Ni}, \mathrm{As}$ and $\mathrm{V}$ were recorded at site 3 while the highest levels of $\mathrm{Zn}$ and $\mathrm{Co}$ were obtained at station 4. Additionally, $\mathrm{Sr}$ revealed its highest content at station 11. The lowest concentrations of $\mathrm{Cu}, \mathrm{Pb}$, $\mathrm{Ni}$ and $\mathrm{Zn}$ were obtained at site 14 , Co at station 15, As at station 8, Sr at station 2 and $\mathrm{V}$ at station 10 (Table 1).

Several studies have been conducted on heavy metal contamination throughout the world (Huang and Lin 2003; De Mora et al. 2004; Zhang et al. 2007). Results of the present survey revealed lower contamination by heavy metals at the Gorgan Bay in comparison with other areas. Heavy metals in surface sediments of a given zone may originate from multiple sources, such as industrial and municipal wastewaters, discharges from mining, irrigation, local rivers and creeks, along with the erosion of rocks and 
Fig. 2 Non-multi-dimensional scaling carried out on abundances of the annelid assemblages (fourth-root transformed) using Bray-Curtis similarity at the Gorgan Bay

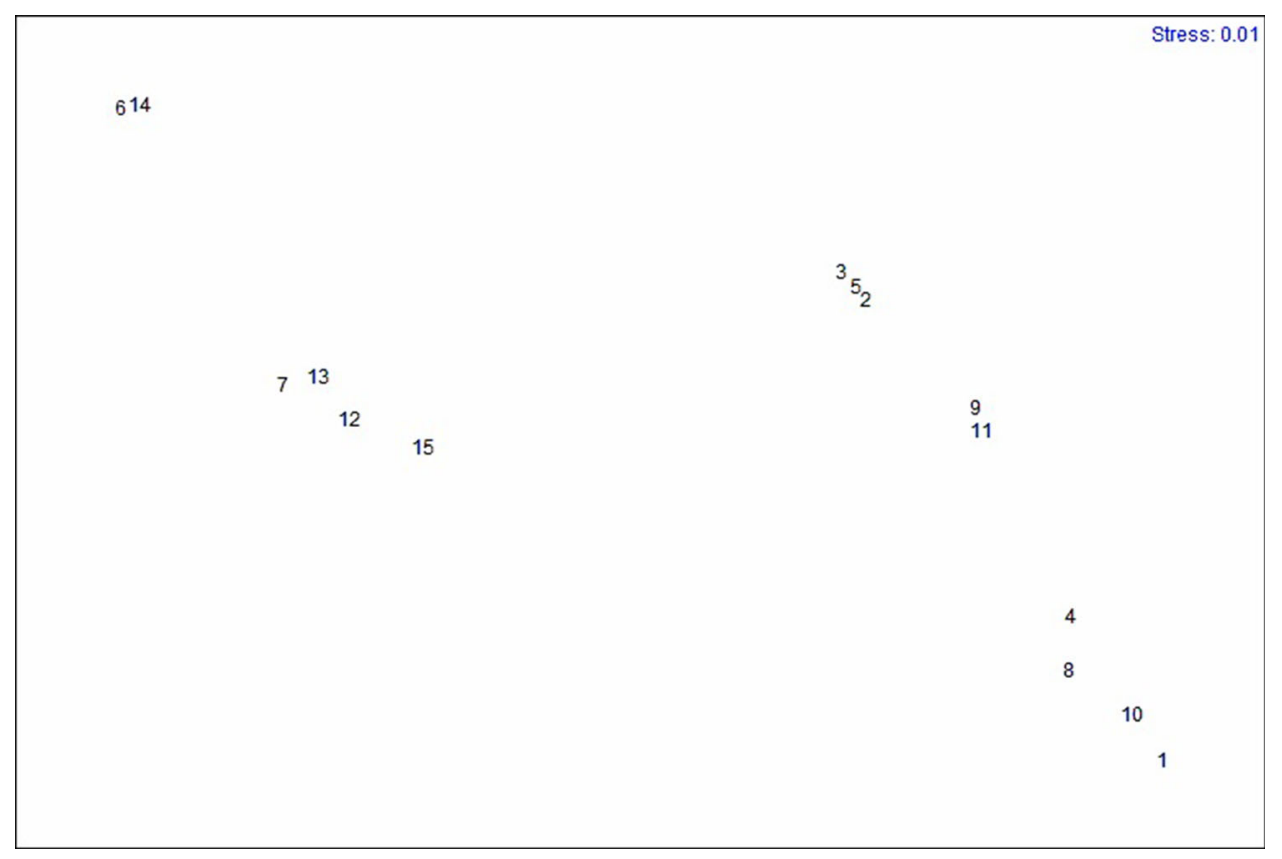

soil parent materials. Gorgan Bay is surrounded by many industries, agricultural and fish farms, dye and papermaking manufactures. These industries use fertilizers, herbicides and fungicides through which copper, lead and chromium can be released to the rivers by precipitation falling, draining water and consequently into the sediments of the Bay. Generally, concentrations of all the heavy metals except for $\mathrm{Sr}$ were high in eastern part of the Gorgan Bay. On the whole, heavy metals concentration in the sediment was in a descending order as:

$\mathrm{Sr}>\mathrm{Zn}>\mathrm{Ni}>\mathrm{V}>\mathrm{Cu}>\mathrm{Pb}>\mathrm{Co}>\mathrm{As}$

In order to predict the heavy metal pollution, a comparative study was performed with sediment quality guidelines (SQGs). Average contents of all the measured heavy metals except As were lower than those of corresponding value of effect range low (ERL), effect range medium (ERM) and probable effect levels (PEL). According to SQGs, adverse biological effects are expected rarely $(<$ ERL), occasionally ( $\geq$ ERL and $<$ ERM/PEL) and frequently ( $\geq$ ERM/PEL) (Long et al. 1995).

As levels at sites 3, 6, 11, 12 and 14 were higher than ERL (8.2), suggesting that As in sediments of these sites would occasionally be expected to cause adverse biological effects on biota.

Pollution load index (PLI) and potential ecological risk (PER)

Results of contamination factors (CFs) and PLI for all metals studied here are presented in Table 3. The highest values of CFs for all the heavy metals except for $\mathrm{Sr}$ were observed at sites 3 and 4, which located near the inlet of Ghareso River while it was at site 11 for Sr. Average PLI in the Gorgan Bay was $1.83 \pm 0.64$. Also, the minimum and the maximum PLI were 0.89 and 2.86, respectively. Stations 3 and 14 had the highest and the lowest of PLI, respectively (Table 3 ). An area with PLI value $>1$ is polluted, whereas PLI value $<1$ indicates no pollution (Chakravarty and Patgiri 2009; Seshan et al. 2010). Similarly, PLI for a zone is calculated by the following equation:

PLI for a zone $=\left(\mathrm{PLI}_{1} \times \mathrm{PLI}_{2} \times \mathrm{PLI}_{3} \times \cdots \times \mathrm{PLI}_{n}\right)^{1 / n}$

where $n$ is the number of sites.

Based on PLI value (1.78), the Gorgan Bay is moderately polluted. Site 3 had the highest PLI (2.86) within the study area, implicating that the sediments of the aforesaid site were strongly polluted by the investigated heavy metals. Site 14 where PLI is 0.89 should be classified without metal pollution.

PER calculated from all metals exception V, Sr and Co, ranged between 18.38 and 60.88. The highest value of PER was recorded at station 3 while the lowest one was recorded at station 14. An average of $36.9 \pm 14.91$ was obtained for PER in the Gorgan Bay (Table 3).

PER can be used to evaluate the potential risk of one metal or a combination of multiple metals. The calculated PER values can be categorized into four classes of PERs: low grade $(\mathrm{PER}<150)$, moderate $(150<\mathrm{PER}<300)$, severe $(300<$ PER $<600)$ and serious (PER >600) (Hakanson 1980). Based on PER results calculated in the present study, Gorgan Bay is classified as a low-risk bay. 


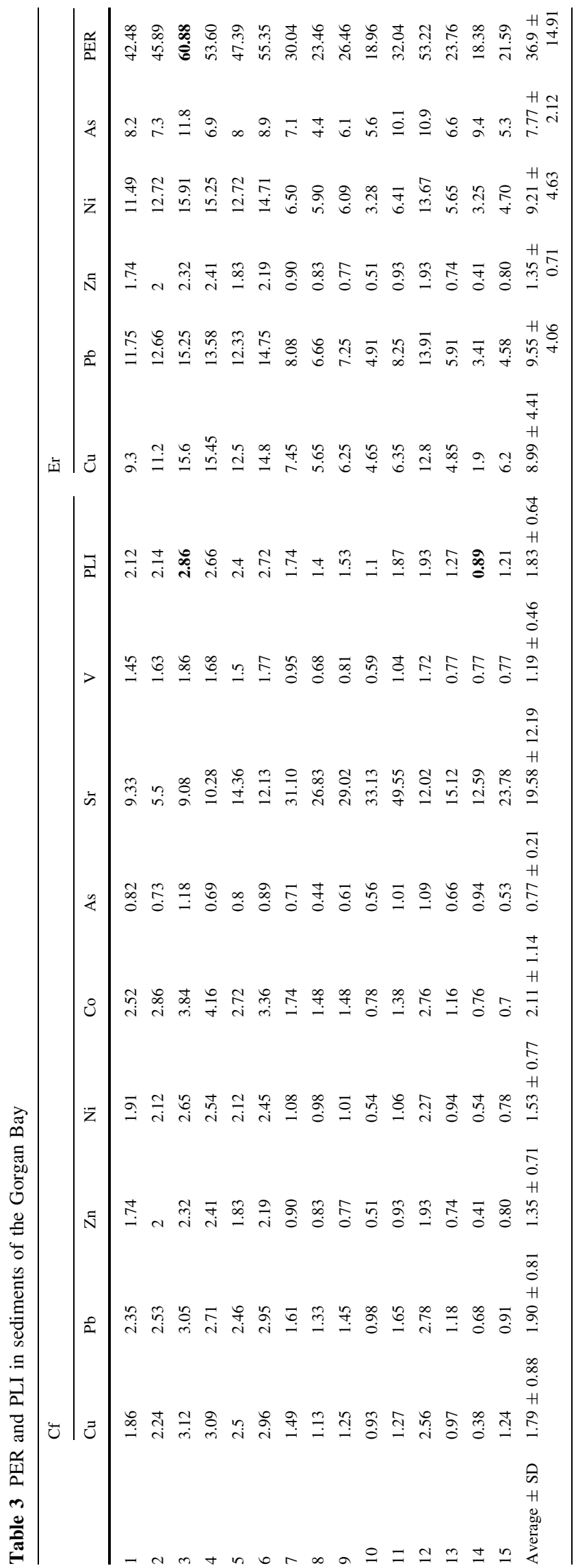

PER and PLI values in the surface sediment show an increase generally from the west to the east, representing that the PERs and pollution increase in the eastern parts of the Gorgan Bay. Sr made the main contribution in PER while $\mathrm{Ni}$ and $\mathrm{Pb}$ had the highest proportion in PLI.

Correlation between heavy metals, physicochemical variables and annelida community structure

Regarding to the statistical test of Pearson, there was a significant positive relationship between all the studied heavy metals with the exception of $\mathrm{Sr} . \mathrm{Cu}, \mathrm{Pb}, \mathrm{Zn}, \mathrm{Ni}$ and Co were significantly negatively correlated with $\mathrm{Sr}$. Moreover, Sr was negatively correlated with As (Table 4).

Positive correlation between heavy metals suggests that metals have common sources, mutual dependence and identical behavior during the transport. In the present study, metals of $\mathrm{Co}, \mathrm{Cu}, \mathrm{Ni}, \mathrm{As}, \mathrm{V}, \mathrm{Pb}$ and $\mathrm{Zn}$ have a common source (human or natural). There are many industries, agricultural and fish farms, dye and paper manufactures using herbicides, fungicides and chemical fertilizers around the Gorgan Bay through which $\mathrm{Ni}, \mathrm{Pb}$ and $\mathrm{Cu}$ can be released into the rivers and consequently sediments of the Bay. Negative correlations between $\mathrm{Sr}$ with other metals suggest that it does not share the above specifically metal traits with others. Strontium is a naturally occurring alkaline earth metal that is common in marine ecosystems and crustal materials (Kasimtseva 2010).

Clay had a negative and significant correlation with As. Sand content revealed a negative significant correlation with $\mathrm{Cu}, \mathrm{Pb}, \mathrm{Zn}, \mathrm{Ni}$ and $\mathrm{Co}$, but $\mathrm{As}$ and $\mathrm{Sr}$ presented a positive correlation with this environmental parameter. There was a positive and significant correlation between silt with $\mathrm{Cu}, \mathrm{Pb}, \mathrm{Zn}, \mathrm{Ni}, \mathrm{Co}$ and $\mathrm{V}$ while a negative and significant correlation was found between silt and $\mathrm{Sr}$. This shows that heavy metals such as $\mathrm{Co}, \mathrm{Cu}, \mathrm{Ni}, \mathrm{As}, \mathrm{V}, \mathrm{Pb}$ and $\mathrm{Zn}$ may be adsorbed on the surface of magnetic minerals which can be found in silt grains. TOM revealed a positive correlation with the whole metals except for Co and As which showed a negative correlation (Table 4). The fine grains, representing the higher ratio of surface to volume and ionic absorption power, are more capable in the absorption of contaminated organic and inorganic materials (McCave 1984; Horowitz and Elrick 1987). This has been proposed that organic matter can affect heavy metals distribution by forming complexes with the metals as these matters contain high specific surface area (Nissenbaum and Swaine 1976). This has been shown that the higher the organic content, the higher the sulfur content, resulting from the precipitation of sulfur during processes of sulfatoreduction induced by $\mathrm{OM}$ decomposition. In anoxic conditions, heavy metals can precipitate with sulfide minerals, and being rapidly removed from the dissolved phase 
therefore increases their value in the sediment (HuertaDiaz and Morse 1992; Aragon and Miguens 2001).

Generally, fine-grained sediments carrying lots of organic matter are more contaminated than that of coarsegrained sediments (De Mora and Sheikholeslami 2002).

Environmental factors can affect on the structure and species diversity of macrobenthic communities and the range of these changes differ in various environments, depending on the level of tolerance to environmental stressors for species (Gray and Pearson 1982; Rygg 1985). Tolerant or opportunistic short-lived species are mostly found in stressed environments while susceptible ones tend to become rare or even extinct in such areas. Somerfield et al. (1994) deduced that sedimentary heavy metals are most strongly correlated with the composition of biological community in the sediment.

So far, several previous researchers have investigated the relation between the levels of heavy metals in sediments and macrobenthic community (Rygg 1985; Hall et al. 1996; Morrisey et al. 1996; Mucha et al. 2003; Burlinson and Lawrence 2007) and demonstrated a negative relationship between these metals and macrobenthic diversity. Rygg (1985) reported a negative correlation between metals $(\mathrm{Pb}, \mathrm{Cu}$ and $\mathrm{Zn})$ with diversity index. Somerfield et al. (1994) indicated that nematode fauna from copper-contaminated sites was less abundant, had a lower richness and a lower species diversity compared with that from less contaminated sites. Similarly, there were negative correlation between $H, d, J$ and $S$ with all of the heavy metal contents except $\mathrm{Sr}$ in our survey (Table 4).

The negative relationships observed between most biotic metrics and metals such as $\mathrm{As}, \mathrm{Cu}, \mathrm{Ni}, \mathrm{V}, \mathrm{Co}, \mathrm{Pb}$ and $\mathrm{Zn}$ indicate that heavy metal contamination is a strong contributing factor to poor biotic condition of the Gorgan Bay. Negative correlation of biotic metrics with these metals (Table 4) also indicated that even at present low levels, heavy metals impacted indices of $H, d, J$ and $S$ for annelida.

Concerning the species tolerance to heavy metals, aquatic organisms are classified into three groups: more susceptible (Crustaceans), less susceptible (Mollusca) and tolerant (Polychaete) (Railken 2004). In the present work, the class Polychaete (N. diversicolor and S. gynobranchiata) and $T$. fraseri were present at most stations. This finding might be due to the resistance ability of these species in response to different ecological conditions at the Gorgan Bay after which they become dominant at all stations.

Although high levels of all heavy metals were found at stations $1,4,8$ and 10 , annelid communities remarkably had heavy densities. This can be partly explained by the fact that the concentrations measured in present study were within the recommended SQGs. The overall lack of a significant negative correlation between heavy metals and density of annelida supports this idea. In general, contaminations would be toxic for living organisms when they exceed over the standard limit (Hall and Frid 1995).

Positive correlation between $\mathrm{Sr}$ with all the biological indices may be due to the fact that this is an essential heavy metal for species. Generally, shortage of essential heavy metals causes physiological disorders and exposure to high doses of heavy metals would result in toxic effects (Connell et al. 1999).

Eigenvalues of the first two RDA axes were high $(0.53$ and 0.29) when compared with subsequent axes (Fig. 3). According to RDA analysis, axes 1 and 2 explained 53.7 and $29.2 \%$ of the variation in species composition, respectively. The first two axes explained $82.9 \%$ of variance of species-environment relation.

Results of RDA indicated a negative correlation between all the species with As which implies that As has a negative significant influence on the studied annelida in the Gorgan Bay (Fig. 3). Effect of As was quite different from the effects of other metals. While this metal was less abundant in the sediments, its toxicity is considerably higher than that of other metals studied here.

Hall and Frid (1995) perceived that polychaetes Capitella capitata and oligochaete Tubificoides sp. were all negatively affected by the presence of $\mathrm{Cu}$ in microcosm experiment. Several studies pointed out that the polychaete worms can tolerate toxic effects of copper (Bryan and Hummerstone 1971; Grant et al. 1989; Rygg 1985). Bryan and Hummerstone (1971) implied that lethal copper levels were higher for polychaete $N$. diversicolor growing in high-copper sediment than those in low-copper sediment. Grant et al. (1989) demonstrated that the elevated tolerance of $N$. diversicolor to copper was inheritable. Our results detected that $T$. fraseri and $N$. diversicolor were negatively correlated with $\mathrm{Cu}$ (Fig. 3).

TOM is important for benthic infauna as it is a potential food source. In brackish water environments, oligochaetes are considered as the most tolerant group to organic pollution (Galope-Bacaltos and San Diego-McGlone 2002).

Abundance of infauna community increases when organic content increases, up to a threshold, beyond which these communities decline (Pearson and Rosenberg 1978). Contaminant content and hypoxia level in organic matters (Amai 1996) may also affect marine infaunal growth and production. This study presented that $S$. gynobranchiata and $N$. diversicolor were negatively correlated with TOM and sand while $T$. fraseri was positively correlated with both variables (Fig. 3). In the present work, it was shown that in addition to heavy metal concentrations, TOM and grain size were two other important determinant factors in abundance of annelida in the Gorgan Bay.

As proposed by Marin et al. (2008), ecological quality status is classified into three levels according to organic 
Table 4 Correlation between heavy metals, biological and physicochemical parameters in sediment of the Gorgan Bay

\begin{tabular}{|c|c|c|c|c|c|c|c|c|c|}
\hline Parameters & $\mathrm{Cu}$ & $\mathrm{Pb}$ & $\mathrm{Zn}$ & $\mathrm{Ni}$ & Co & As & $\mathrm{Sr}$ & $\mathrm{V}$ & Clay \\
\hline $\mathrm{Pb}$ & $0.963 * *$ & & & & & & & & \\
\hline $\mathrm{Zn}$ & $0.975 * *$ & $0.971^{* *}$ & & & & & & & \\
\hline $\mathrm{Ni}$ & $0.975 * *$ & $0.985 * *$ & $0.994 * *$ & & & & & & \\
\hline Co & $0.962 * *$ & $0.955^{* *}$ & $0.974 * *$ & $0.975 * *$ & & & & & \\
\hline As & $0.454 *$ & $0.555^{*}$ & $0.475^{*}$ & $0.522 *$ & $0.459^{*}$ & & & & \\
\hline $\mathrm{Sr}$ & $-0.535^{*}$ & $-0.537 *$ & $-0.637 * *$ & $-0.635^{* *}$ & $-0.597 * *$ & -0.246 & & & \\
\hline V & $0.942 * *$ & $0.973 * *$ & $0.973 * *$ & $0.980 * *$ & $0.937 * *$ & $0.641 * *$ & $-0.628 * *$ & & \\
\hline Clay & 0.142 & 0.030 & 0.004 & -0.017 & -0.042 & $-0.452^{*}$ & 0.269 & -0.082 & \\
\hline Sand & $-0.629 * *$ & $-0.515^{*}$ & $-0.535^{*}$ & $-0.500^{*}$ & $-0.510 *$ & 0.129 & 0.160 & -0.437 & $-0.778 * *$ \\
\hline Silt & $0.819 * *$ & $0.739 * *$ & $0.789 * *$ & $0.754 * *$ & $0.788 * *$ & 0.164 & $-0.447^{*}$ & $0.711 * *$ & 0.366 \\
\hline Depth & 0.289 & 0.345 & 0.315 & 0.301 & 0.333 & -0.118 & -0.222 & 0.280 & 0.411 \\
\hline TOM & 0.026 & -0.101 & -0.112 & -0.113 & -0.208 & -0.125 & 0.352 & -0.129 & $0.623 * *$ \\
\hline$T$ & -0.090 & -0.122 & -0.199 & -0.160 & -0.135 & 0.095 & 0.316 & -0.154 & 0.046 \\
\hline$S$ & -0.113 & -0.017 & -0.077 & -0.073 & -0.065 & -0.413 & 0.169 & -0.166 & 0.126 \\
\hline$N$ & -0.023 & 0.015 & 0.033 & -0.006 & 0.066 & -0.327 & 0.180 & -0.091 & 0.119 \\
\hline$d$ & -0.279 & -0.250 & -0.337 & -0.280 & -0.283 & -0.399 & 0.270 & -0.404 & 0.089 \\
\hline$J$ & -0.231 & -0.351 & -0.344 & -0.341 & -0.391 & $-0.466^{*}$ & 0.310 & -0.433 & $0.583^{*}$ \\
\hline$H$ & -0.290 & -0.331 & -0.368 & -0.350 & -0.360 & $-0.576^{*}$ & 0.331 & $-0.474^{*}$ & 0.434 \\
\hline Parameters & Sand & Silt & Depth & TOM & $T$ & $S$ & $N$ & $d$ & $J$ \\
\hline \multicolumn{10}{|l|}{$\mathrm{Pb}$} \\
\hline \multicolumn{10}{|l|}{$\mathrm{Zn}$} \\
\hline \multicolumn{10}{|l|}{$\mathrm{Ni}$} \\
\hline \multicolumn{10}{|l|}{ Co } \\
\hline \multicolumn{10}{|l|}{ As } \\
\hline \multicolumn{10}{|l|}{$\mathrm{Sr}$} \\
\hline \multicolumn{10}{|l|}{$\mathrm{V}$} \\
\hline \multicolumn{10}{|l|}{ Clay } \\
\hline \multicolumn{10}{|l|}{ Sand } \\
\hline Silt & $-0.870 * *$ & & & & & & & & \\
\hline Depth & $-0.515^{*}$ & 0.440 & & & & & & & \\
\hline TOM & -0.313 & -0.026 & -0.315 & & & & & & \\
\hline$T$ & 0.148 & -0.256 & -0.203 & 0.107 & & & & & \\
\hline$S$ & -0.019 & -0.070 & 0.004 & -0.058 & -0.233 & & & & \\
\hline$N$ & -0.197 & 0.199 & 0.117 & -0.094 & -0.387 & $0.742 * *$ & & & \\
\hline$d$ & 0.211 & -0.382 & -0.297 & 0.191 & 0.103 & $0.656^{* *}$ & 0.236 & & \\
\hline$J$ & -0.235 & -0.110 & -0.250 & $0.717 * *$ & -0.092 & 0.323 & 0.240 & $0.559 *$ & \\
\hline$H$ & -0.088 & -0.210 & -0.214 & $0.453^{*}$ & -0.092 & $0.705 * *$ & $0.471 *$ & $0.806 * *$ & $0.859 * *$ \\
\hline
\end{tabular}

$T$ temperature, TOM total organic matter, $S$ number of species, $N$ number of individual, $d$ species richness (Margalef's index), $J$ evenness Pielou's, $H$ species diversity (Shannon-Weaner index)

** Correlation is significant at the 0.01 level

* Correlation is significant at the 0.05 level

matter content: high good (less than $5 \%$ ), moderate (between 5 to $10 \%$ ) and poor bad (greater than $10 \%$ ). As illustrated in Table 1, TOM contents of all stations were less than the presented above range (1.75-9\%) in the present study. According to Marin et al. (2008), stations 1, $2,3,4,7,8,9,10,12,13$ and 14 showed a high-good quality while the remaining stations 5, 6, 11 and 15 should be classified as moderate.

Salinity is one of the most important parameter affecting both physicochemical variables and biology of living organisms within an estuary. Attrill and Rundle (2002) exhibited that salinity variation is the major factor 


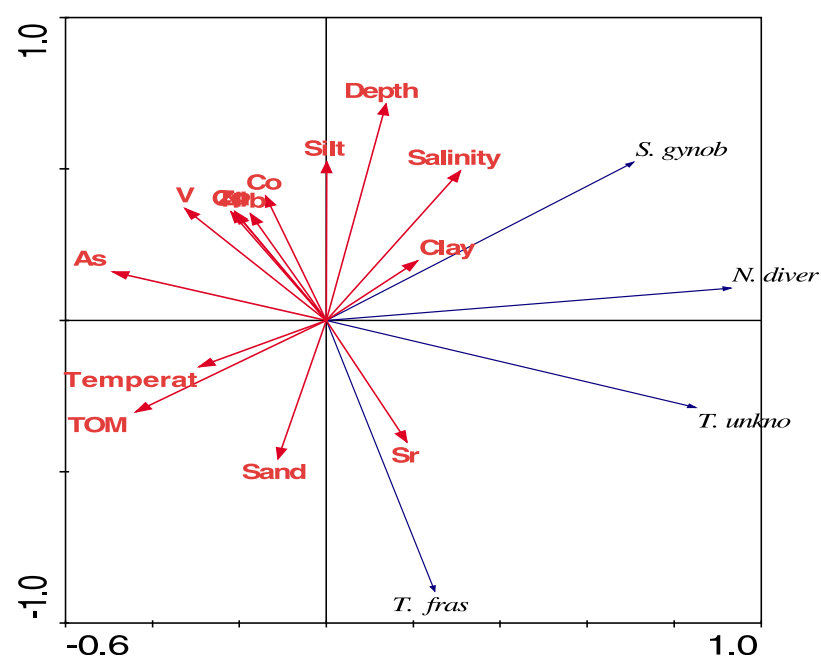

Fig. 3 Results of RDA between annelids assemblage, environmental parameters and heavy metals at the Gorgan Bay. The arrows indicate the direction of increase for the variables studied. The angles between variables reflect their correlations (angles near $90^{\circ}$ indicate no correlation, angles near $0^{\circ}$ indicate high positive correlation and angles near $180^{\circ}$ indicate high negative correlation)

influencing distribution of organisms in estuaries. Fluctuating salinity conditions cause a level of stress that prevents organisms maximizing their potential distribution. Annelida assemblage studied here, in the present work, is directly influenced by salinity due to their low mobility. Our result displayed that $S$. gynobranchiata and $N$. diversicolor were positively correlated with salinity (Fig. 3).

\section{Conclusion}

This study provides important information on annelida communities in relation to environmental factors and heavy metals in surface sediments of the Gorgan Bay. Sr and As had the highest and the lowest concentration levels in the surface sediment of Gorgan Bay, respectively. Level of As at some sites was higher than ERL. This may cause toxicity to certain exposed organisms. According to PER calculated in this study, Gorgan Bay is classified as low risk.

No single mechanism has been able to explain faunal patterns observed across many different environments, and at any given location, indicating that a number of different interacting factors are involved. Because in the present work, the annelida assemblages were investigated only in late spring, more studies during other seasons, within at least 2 or 3 successive years and with increasing the sample size, are needed to fully understand how annelida respond to heavy metals contamination and other environmental parameters and how they can be used to indicate the level of heavy metals.

Acknowledgments We are grateful to Dr. Leo Arciaga and Dr. Melissa Morrison, ACME Analytical Laboratories Ltd. in Canada, for providing information on the methods and standard specifications which helped us in the completion of this paper.

\section{References}

Abrantes A, Pinto F, Moreira M (1999) Ecology of polychaete Nereis diversicolor, in the Cannal de Mira (Ria de averio, Portugal). Population dynamics, production and oogenic cycle. Acta Oceanol 20(4):267-283

Amai K (1996) Temporal tolerance of larval Theora fragilis (Bivalvia: Semelidae) to hypoxic conditions. Fish Sci 62:996-997

Aragon G, Miguens F (2001) Microscopic analysis of pyrite in the sediments of two Brazilian mangrove ecosystems. Geo-Mar Lett 21:157-161

Attrill MJ, Rundle SD (2002) Ecotone or ecocline: ecological boundaries in estuaries. Estuary Coast Shelf Sci 55:929-936

Borja A, Bricker SB, Dauer DM, Demetriades NT, Ferreira JG, Forbes AT, Hutchings P, Jia X, Kenchington R, Marques JC, Zhu C (2008) Overview of integrative and methods in assessing ecological integrity in estuarine and coastal systems worldwide. Mar Pollut Bull 56:1519-1537

Brown CL, Luoma SN (1995) Use of the euryhaline bivalves Potomocorbula amurensis as a biosentinel species to assess trace metal concentrations in San Francisco Bay. Mar Ecol Prog Ser 12:129-142

Bryan GW, Hummerstone LG (1971) Adaptation of the polychaete Nereis diversicolor to estuarine sediments containing high concentrations of heavy metals, I. General observations and adaptation to copper. J Mar Biol Assoc UK 51:845-863

Burlinson FC, Lawrence AJ (2007) A comparison of acute and chronic toxicity tests used to examine the temporal stability of a gradient in copper tolerance of Hediste diversicolor from the $\mathrm{Fal}$ estuary, Cornwall, UK. Mar Pollut Bull 54:66-71

Chakravarty M, Patgiri AD (2009) Metal pollution assessment in sediments of the Dikrong River, NE India. J Hum Ecol 27(1):63-67

Clarke RK, Warwick RM (2001) Changes in marine communities; an approach to statistical analysis and interpretation, 3rd edn. Plymouth Routines In Multivariate Ecological Research; PRIMER-E Ltd., Plymouth

Connell DW, Lam P, Richardson B, Wu R (1999) Introduction to ecotoxicology. Blackwell Science, Oxford

Dauvin J-C (2008) Effects of heavy metal contamination on the macrobenthic fauna in estuaries: the case of the Seine estuary. Mar Pollut Bull 57:160-169

De Mora SD, Sheikholeslami MR (2002) ASTP: contaminant screening program: final report: interpretation of Caspian Sea sediment data. Caspian Environment Program (CEP), pp 1-27

De Mora SJ, Sheikholeslami MR, Wyse E, Azemard S, Cassi R (2004) An assessment of metal contamination in coastal sediments of the Caspian Sea. Mar Pollut Bull 48:61-77

Díaz-Castaneda V, Harris LH (2004) Biodiversity and structure of the polychaete fauna from soft bottoms of Bahia Todos Santos, Baja California, Mexico. Deep Sea Res II 51:827-847

Fauchald K (1977) The polychaete worms. Definitions and keys to orders, families and genera. Nat. Hist Mus Los Angel Ctry Sci Ser 28:1-188

Frost JW, Schleicher T, Craft C (2009) Effects of nitrogen and phosphorus additions on primary production and Invertebrate densities in a Georgia (USA) tidal freshwater marsh. Wetlands 29:196-203

Fu C, Guo J, Pan J, Qi J, Zhou W (2009) Potential ecological risk assessment of heavy metal pollution in sediments of the Yangtze 
river within the Wanzhou section, China Biology. Trace Elem Res 129:270-277

Galope-Bacaltos DG, San Diego-McGlone ML (2002) Composition and spatial distribution of infauna in a river estuary affected by fishpond effluents. Mar Ecol Prog Ser 44:816-832

Gamito S (2008) Three main stressors acting on the Ria Formosa lagoonal system (Southern Portugal): physical stress, organic matter pollution and the land-ocean gradient. Estuary Coast Shelf Sci 77:710-720

Gesteira JLG, Dauvin JC, Salvande Fraga M (2003) Taxonomic level for assessing oil spill effects on soft-bottom sublittoral benthic communities. Mar Pollut Bull 46:562-572

Goto D, Wallace WG (2010) Relative importance of multiple environmental variables in structuring benthic macroinfaunal assemblages in chronically metal-polluted salt marshes. Mar Pollut Bull 60:363-375

Grant A, Hateley JG, Jones NV (1989) Mapping the ecological impact of heavy metals on the estuarine polychaete Nereis diversicolor using inherited metal tolerance. Mar Pollut Bull 20:235-238

Gray JS, Pearson TH (1982) Objective selection of sensitive species indicative of pollution-induced changes in benthic communities. I. Comparative methodology. Mar Ecol Prog Ser 9:111-119

Guo Weihua, Liu Xianbin, Liu Zhanguang, Li Guofeng (2010) Pollution and potential ecological risk evaluation of heavy metals in the sediments around Dongjiang Harbor, Tianjin. Procedia Environ Sci 2:729-736

Hakanson L (1980) An ecological risk index for aquatic pollution control, a sediment-ecological approach. Water Res 14:975-1001

Hall JA, Frid CLJ (1995) Responses of estuarine benthic meiofauna in copper-contaminated sediments to remediation of sediment quality. Mar Pollut Bull 30:694-700

Hall JA, Frid CLJ, Proudfoot RK (1996) Effects of metal contamination on macrobenthos of two North Sea estuaries. ICES J Mar Sci 53:1014-1023

Horowitz AJ, Elrick KA (1987) The relation of stream sediment surface area, grain size and composition to trace element chemistry. Appl Geochem 2:437-451

Huang KM, Lin S (2003) Consequences and implication of heavy metal spatial variations in sediments of the Keelung River drainage basin, Taiwan. Chemosphere 53:1113-1121

Huerta-Diaz MA, Morse JW (1992) Pyritization of trace metals in anoxic marine sediments. Geochim Cosmochim Acta 56:2681-2702

Kasimtseva NV (2010) Removal of arsenic and strontium from aqueous solution using iron oxide coated zeolitized tuff. M.S. Thesis, Department of Water Resources Management, University of Nevada, Las Vegas, Paper 735

Khan SA, Murugesan P, Lyla PS (2004) A new indicator macroinvertebrate of pollution and utility of graphical tools and diversity indices in pollution monitoring studies. Curr Sci 87:1508-1510

Lepš J, Šmilauer P (2003) Multivariate analysis of ecological data using CANOCO. Cambridge University Press, Cambridge

Lindholm R (1987) A practical approach to sedimentology. Allen and Unwin, London, pp 1-278

Long ER, MacDonald DD, Smith SL, Calder FD (1995) Incidence of adverse biological effects within ranges of chemical concentrations in marine and estuarine sediments. Environ Manag 19:18-97

Lotufo GR, Farrar JD, Inouye LS, Bridges TS, Ringelberg DB (2001) Toxicity of sediment-associated nitroaromatic and cyclonitramine compounds to benthic invertebrates. Environ Toxicol Chem 20:1762-1771
Marin V, Moreno M, Vassallo P, Vezzulli L, Fabiano M (2008) Development of a multistep indicator-based approach (MIBA) for the assessment of environmental quality of harbours. ICES J Mar Sci 65:1436-1441

McCave IN (1984) Size spectra and aggregation of suspended particles in the deep ocean. Deep Sea Res 31:329-352

Morrisey DJ, Underwood AJ, Howitt L (1996) Effects of copper on the faunas of marine soft-sediments: a field experimental study. Mar Biol 125:199-213

Mucha AP, Vasconcelos M, Bordalo AA (2003) Macrobenthic community in the Douro estuary: relations with trace metals and natural sediment characteristics. Environ Pollut 121:169-180

Nissenbaum A, Swaine DJ (1976) Organic-metal interactions in recent sediments: the role of humic substances. Geochim Cosmochim Acta 40:809-816

Pearson TH, Rosenberg R (1978) Macrobenthic succession in relation to organic enrichment and pollution of the marine environment. Oceanogr Mar Biol Annu Rev 16:229-311

Pinder AM, Halse SA, McRae JM, Shiel RJ (2005) Occurrence of aquatic invertebrates of the wheatbelt region of Western Australia in relation to salinity. Hydrobiologia 543:1-24

Railken AI (2004) Marine biofouling: colonization processes and defenses. CRC, Boca Raton

Rygg B (1985) Effect of sediment copper on benthic fauna. Mar Ecol Prog Ser 25:83-89

Scaps P (2002) A review of the biology, ecology and potential use of the common ragworm; Hediste diversicolor; (O.F. Müller) (Annelida: Polychaeta). Hydrobiologia 470:203-218

Seshan BRR, Natesan U, Deepthi K (2010) Geochemical and statistical approach for evaluation of heavy metal pollution in core sediments in southeast coast of India. Int $\mathrm{J}$ Environ Sci Technol 7(2):291-306

Somerfield PJ, Gee JM, Warwick RM (1994) Benthic community structure in relation to an instantaneous discharge of waste water from a tin mine. Mar Pollut Bull 28:363-369

Suresh G, Ramasamy V, Meenakshisundaram V, Venkatachalapathy R, Ponnu-samy V (2011) Influence of mineralogical and heavy metal composition on natural radionuclide contents in the river sediments. Appl Radiat Isot 69:1466-1474

ter Braak CJF, Šmilauer P (2002) CANOCO reference manual and CanoDraw for Windows user's guide: software for canonical community ordination (version 4.5). Microcomputer Power, Ithaca, New York

Van Hoey G (2004) Macrobenthic community structure of softbottom sediments at the Belgian Continental Shelf. Estuary Coast Shelf Sci 59:599-613

Vincx M, Heip C (1987) The use of meiobenthos in pollution monitoring studies: a review. ICES, CM E33L(1166):1-18

Wentworth CK (1992) A scale of grade and class terms for clastic sediments. J Geol 30:377-392

Wilhm JL, Dorris TC (1966) Species diversity of benthic macroinvertebrates in a stream receiving domestic and oil refinery effluents. Am Midl Nat 76:427-449

Zhang LP, Ye X, Feng H, Jing YH, Ouyang T, Yu XT, Liang RY, Gao CT, Chen WQ (2007) Heavy metal contamination in western Xiamen Bay sediments and its vicinity, China. Mar Pollut Bull 54:974-982

Zorita I, Apraiz I, Ortiz-Zarragoitia M, Orbea A, Cancio I, Soto M, Marigómez I, Cajaraville MP (2007) Assessment of biological effects of environmental pollution along the NW Mediterranean Sea using mussels as sentinel organisms. Environ Pollut 148:236-250 